\title{
IMPROVING THE MECHANICAL PROPERTIES AND APATITE FORMATION ABILITY OF NANO- HYDROXYAPATITE/POLYAMIDE 66 COMPOSITE FOR USING AS THE INTERVERTEBRAL FUSION CAGE
}

\section{HAMID REZA JANGHORBAN}

Amin Hospital

Ebn-e-Sina St.

Isfahan

Iran

e-mail: hamidrezajanghorban@yahoo.com

\begin{abstract}
One of the significant challenges in designing an ideal cage is the mechanical modulus mismatch between the implant and surrounding host tissue which results in stress shielding. In this study, a nano-hydroxyapatite/polyamide 66 (n-HA/PA66) composite with mechanical properties close to spongy bone to be designed and characterized as an intervertebral fusion cage to perform spinal fusion between vertebrae in the lumbar spine. A pure natural nanohydroxyapatite (n-HA) powder was prepared by annealing bovine bone at $1000^{\circ} \mathrm{C}$ followed by $10 \mathrm{~h}$ mechanical alloying. The nano-hydroxyapaptite/ polyamide 66 and polyamide 66 (PA66) cage were prepared by injection method. X-ray diffraction (XRD), scanning electron microscopy (SEM), and energy dispersive spectrophotometer (EDS) were used to characterize the powder and composites samples. The results showed that addition of $20 \%$ nanohydroxyapaptite results in the improvement of both mechanical and bioactivity properties. The optimum n-HA/PA66 exhibited the compressive strength and elastic modulus of $46.98 \pm 2 \mathrm{MPa}$ and $1.53 \pm 0.3 \mathrm{GPa}$, respectively, which is close
\end{abstract}

Keywords and phrases: cage, polyamide, hydroxyapatite, back pain.

Received January 28, 2017; Revised February 23, 2017

(C) 2017 Scientific Advances Publishers 
to spongy bone. In addition, observation of the superior apatite formation ability of n-HA/PA66 compared to PA66 indicates that it can be used as a bone replacement material.

\section{Introduction}

Back pain is very common problem among people around the world $[1,2]$. In some specific cases, surgery would be suggested as a healing procedure. Surgery of the spine is a major challenging operation. In large spine defects, when the gaps are huge, a bone graft can stimulate healing [1-4]. In the bone graft, autograft, allograft and synthetic substitute (implants) can replace the degenerative disc disease in the spine to relieve back pain; and it is known as spinal fusion [5, 6]. Disadvantages of autografting and allografting, are limited by the amount of suitable bone and lack of donors, require double operations, increase infection and osteomyelitis, disease transmission and immune response [7, 8]. Hence, synthetic devices have been offered as alternative methods to motivate the bone tissue growth [9]. The intervertebral fusion cage has been designed as a new device to perform the spinal fusion, and in the past 30 decades, it has been produced by metal, polymer, ceramic and composite of these materials $[10,12]$. In the previous studies, titanium mesh cage was used successfully and indicated high fusion rates. However, several disadvantages including stress shielding, corrosion, high incidence, subsidence and creating problems in radiography procedure limited its use as an ideal cage [13, 14]. Therefore, use of polymer and ceramic suggested new approaches to make the cage devices. Polyamide (PA) was recognized as a synthetic polymer with excellent biocompatibility due to its chemical networks and active group similarity with proteins and collagen. Polyamide also has excellent mechanical properties resulting from strong hydrogen bonds between the amide groups in PA macromolecules. However, PA is bio inert and does not react or form a bond with bone [15, 16]. Therefore, it is a major drawback of this polymer. Hydroxyapatite (HA) is well known as the main type of calcium phosphate group due to its chemical similarity to mineral portion of bone 
tissue. Unique bioactivity, biocompatibility and its excellent osteoconductive capability make it a suitable ceramic material to be used as hard tissue regeneration $[17,18]$. Using composite of polyamide and HA for designing the intervertebral fusion cage with improved mechanical and biological properties is the main aim of this study. Therefore, the mechanical properties and in vitro bioactivity of $\mathrm{HA} /$ polyamide composite cage were investigated. In addition, the mechanical properties of n-HA/PA66 cage were compared with traditional polyetheretherketone (peek) cage.

\section{Materials and Method}

\subsection{Preparation of nano-HA powder}

In order to prepare the natural nano-HA powder, the femur of bovine was purchased and boiled for $5 \mathrm{~h}$ in distilled water to remove the visible tissue and marrow's bovine. Then, an electric furnace was used to anneal the bovine's bone at $1000^{\circ} \mathrm{C}$ for $3 \mathrm{~h}$. The obtained matter was ball milled for $10 \mathrm{~h}$ in zirconia vial with five $2 \mathrm{~cm}$ zirconia balls. The ball/powder weight ratio was $10: 1$ and disc rotational speed was set $250 \mathrm{rpm}$.

\subsection{Preparation of nano-HA/PA66 composite cage}

The 20wt\% HA-PA66 cage and pure PA66 cage were prepared by injecting the molten liquid of n-HA/PA66 into the steel mold. Figure 1 shows the prepared cages. 

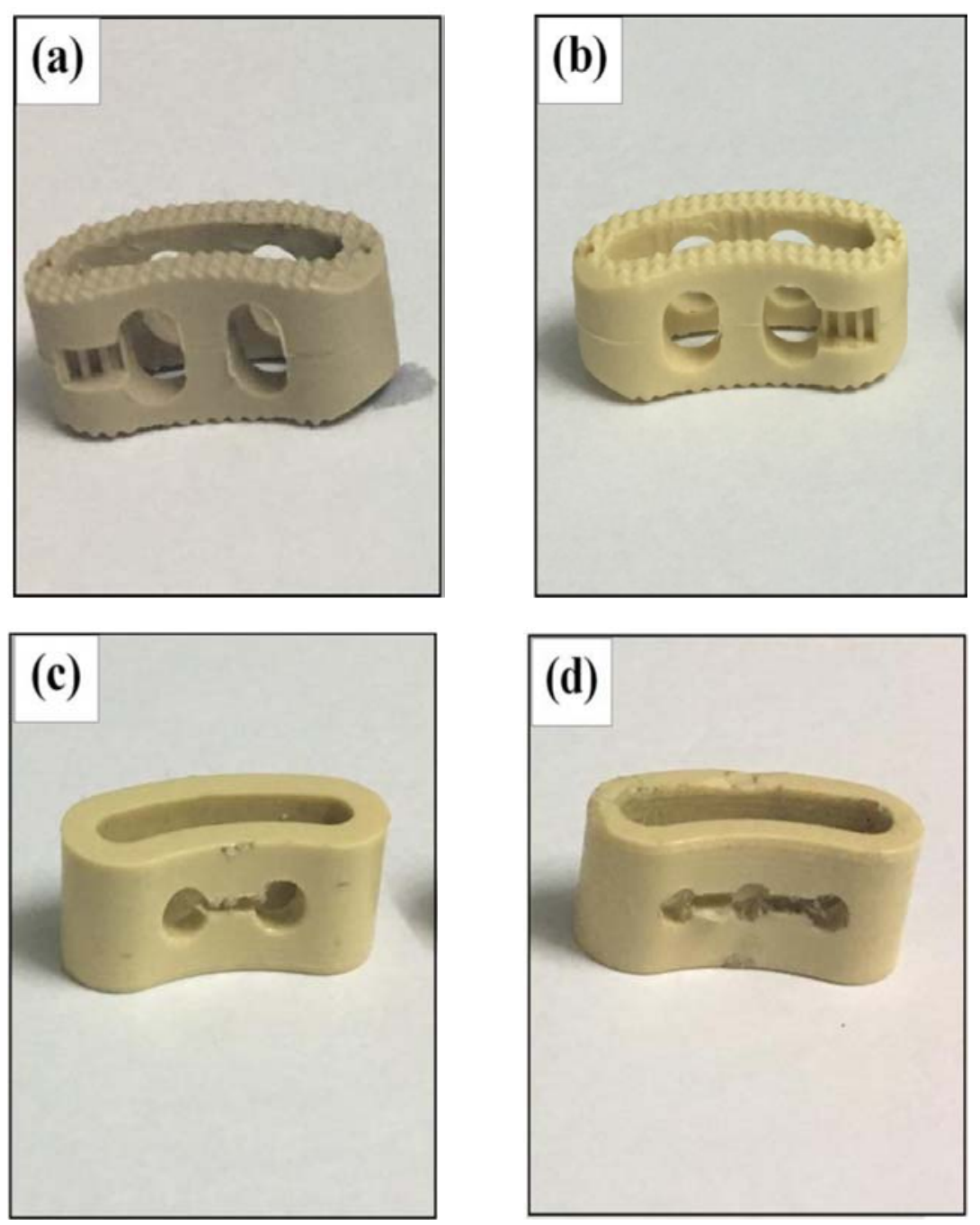


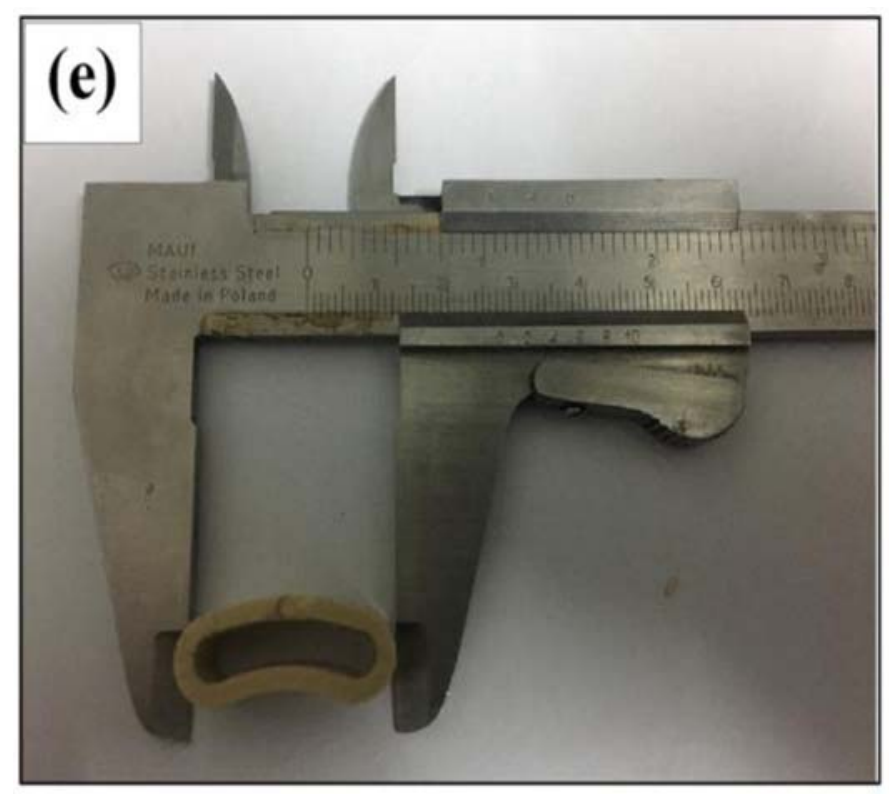

Figure 1. (a) The PA66, (b) n-HA/PA66 (without slot between holes), (c) n-HA/PA66 (with slot between holes), (d) n-HA/PA66 (three holes), and (e) it is a hollow elliptical with $27 \mathrm{~mm}$ in larger outer diameter and $21 \mathrm{~mm}$ in inner diameter.

\subsection{Characterization of powder and composite}

Crystallite size and phase transformation of powder were assigned by X-ray diffraction (XRD, X'Pert Philips) with $\mathrm{CuK} \alpha(\lambda=0.154 \mathrm{~nm})$ radiation at $40 \mathrm{kV}$ and $30 \mathrm{~mA}$. The XRD patterns were recorded at the $2 \Theta$ range of $20-80^{\circ}$ with $0.05^{\circ}$ step size and 1 s time per step. Williamson-Hall method was used for crystallite size measuring [19].

$$
\beta \cos \theta=\frac{0.9 \lambda}{D}+2 \varepsilon \sin \theta,
$$

where $\theta$ is the Bragg diffraction angle, $\varepsilon$ is the internal strain, $D$ is the crystallite size, $\lambda$ is the wavelength of the radiation, $\beta$ is the diffraction peak width at half maximum intensity, and 0.9 is the Scherrer constant. The bioactivity of the produced cage was investigated by Bohner et al. 
[20] protocol and the nano-HA/polyamide and polyamide produced cage was immersed in simulated body fluid (SBF) for 28 days. Scanning electron microscopy (SEM, Philips XL30 at an acceleration voltage of $30 \mathrm{kV}$ ) and energy dispersive spectrophotometer (EDS) were used to investigate the apatite formation and deposition followed by immersing the cage in SBF. The compressive strength and modulus of n-HA/PA66 and PA66 produced cage were evaluated by universal testing machine ((Hounsfield: H25KS) at a crosshead speed of $1 \mathrm{~mm} / \mathrm{min}$.

\section{Results}

The XRD pattern of nano-HA, after it was annealed at $1000^{\circ} \mathrm{C}$ followed by $10 \mathrm{~h}$ ball mill, was shown in Figure 2. As can be seen in this pattern, all the peaks correspond to the characteristic peaks of hydroxyapatite phases (JCPDS 01-086-0740). Therefore, in this study, we succeed in inducing the natural HA powder of bovine bone in nano range size that has more chemical and structural similarity to mineralized bone tissue [21]. The crystallite size of hydroxyapatite powder was measured $61 \pm 2 \mathrm{~nm}$. Nano-crystalline ceramics in comparison to micro particle ceramics have improved properties such as high contact area, high diffusion rates, reduced sintering time or temperature, and high mechanical properties. For example, nano-crystalline HA improves osteoblast cells adhesion, differentiation, proliferation, osteo-integration and $\mathrm{Ca}$ containing minerals are deposited on its surface better than micro-crystalline HA [19, 21, 22]. Hence, nano-scale ceramic materials are preferred to use as replacement and regeneration materials. Figure 3 shows the force-extension curve of nano-HA/PA66 (with different designs), peek, PA66, and comparisons of the mechanical properties of different cages including those prepared in this study and spongy and cortical bone are presented in Table 1. As can be seen from Table 1, the presence of the ceramic phase and design of holes have an important effect on the mechanical properties. Based on the obtained results, addition of $20 \%$ n-HA in PA66 matrix (without hole) enhanced both 
compressive strength and modulus from 57.27 to 90.54 and 1.55 to 8.19 and close them to cortical bone with compressive strength and modulus in the range of $130-180 \mathrm{MPa}$ and $7-30 \mathrm{GPa}$, respectively. According to Figure 1(b)-(d) and results of Table 1, it can be noted that making holes in the cage walls resulted in reducing the elastic modulus close to spongy bone, which has a compressive strength and elastic modulus in the range of 4-12MPa and 0.1-1.1GPa, respectively.

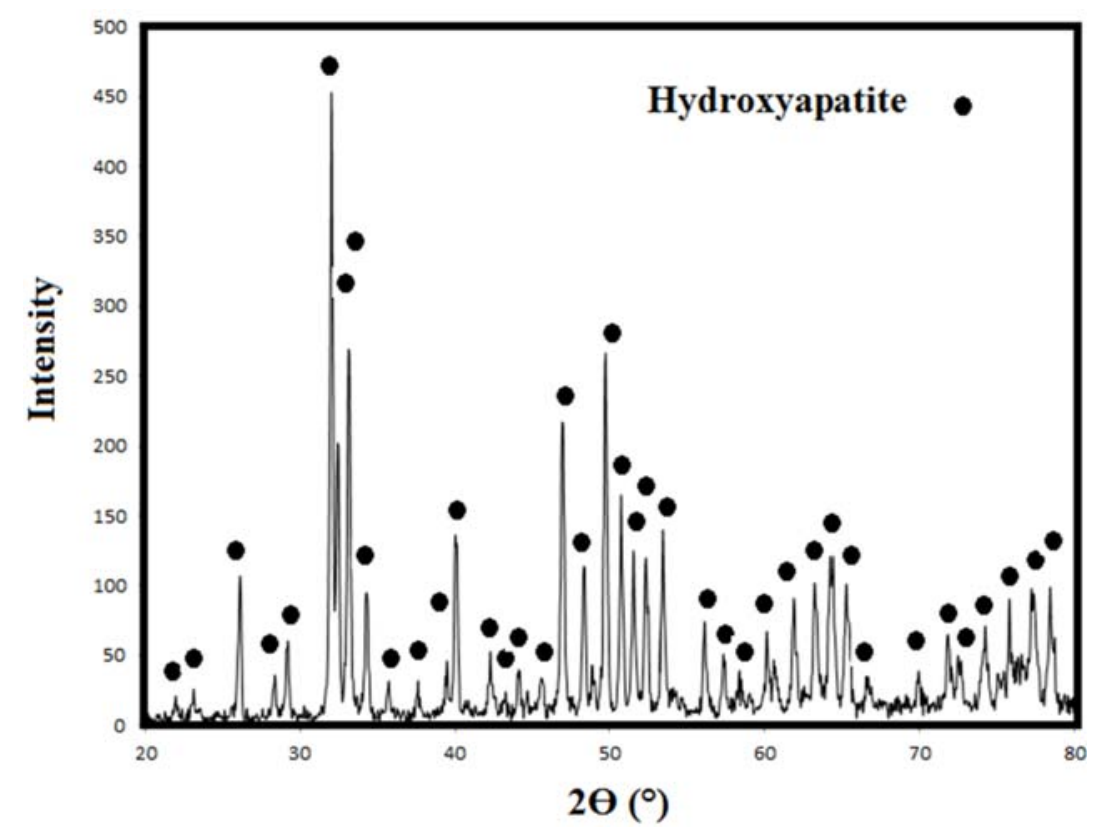

Figure 2. X-ray diffraction pattern of natural nano-HA powder. 


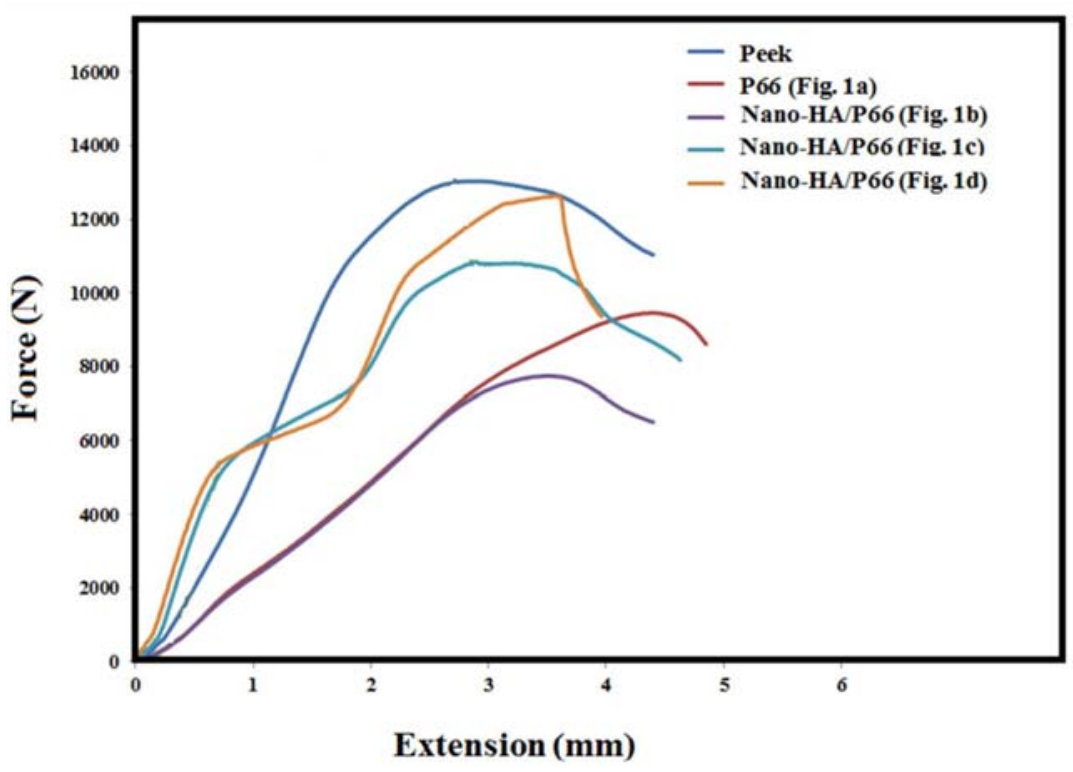

Figure 3. Force-extension curve of nano-HA/PA66 (different design), PA66 and peek cage.

Table 1. Mechanical properties of preparation cage, spongy and cortical bone (mean \pm standard deviation)

\begin{tabular}{lcl}
\hline Samples & $\begin{array}{c}\text { Compressive } \\
\text { strength (MPa) }\end{array}$ & $\begin{array}{c}\text { Elastic modulus } \\
\text { (GPa) }\end{array}$ \\
\hline Peek & $79 \pm 1$ & $3.95 \pm 1$ \\
PA66 (Figure 1(a)) & $57.27 \pm 1.5$ & $1.55 \pm 0.8$ \\
n-HA/PA66 (without hole) & $90.54 \pm 3$ & $8.19 \pm 1.2$ \\
n-HA/PA66 (Figure 1(b)) & $46.98 \pm 2$ & $1.53 \pm 0.3$ \\
n-HA/PA66 (Figure 1(c)) & $65.75 \pm 1$ & $5.25 \pm 0.42$ \\
n-HA/PA66 (Figure 1(d)) & $76.54 \pm 1.53$ & $5.75 \pm 0.5$ \\
Spongy bone & $4-12[23-25]$ & $0.1-1.1[23-25]$ \\
Cortical bone & $130-180[23-25]$ & $7-30[23-25]$ \\
\hline
\end{tabular}

Some researchers reported the successful fabrication of n-HA/PA66 composite for various clinical applications. Xu et al. [12] synthesized the n-HA/PA66 scaffolds by thermal pressing and injection molding 
techniques. The n-HA/PA66 scaffold was implanted into muscle and tibiae of rabbits and the results indicated that at 2 weeks, osteogenesis was detected in porous n-HA/PA66 composite. The study indicated that the scaffolds could facilitate cell adhesion, differentiation and proliferation, and help with fibro vascular and nerve colonization. Also, the compressive strength and modulus of the composite with $64.5 \mathrm{wt} \% \mathrm{n}$ HA content were $117 \mathrm{MPa}$ and $5.6 \mathrm{GPa}$, respectively which is still far away from the mechanical properties of spongy bone and probability of stress shielding phenomenon is existed. Zhang et al. [10] fabricated a novel ternary composite using carbon fibers to reinforce a nanohydroxyapatite/polyamide 66 composite (HA/PA). They could successfully produce these composites with different carbon fibers content with random orientation in HA/PA66 matrix. The compressive strength and modulus was found to be in the range of $116-212 \mathrm{MPa}$ and 2.9-5.8GPa. Despite, these mechanical properties is higher than what needing for cage devises.

Therefore, n-HA/PA66 (Figure 1(b)) fabricated in this study, with the mechanical properties (compressive strength $46.98 \pm 2$ and modulus $1.53 \pm 0.3 \mathrm{GPa}$ ) close to spongy bone tissue has significant potential as intervertebral fusion cage in human body.

Figure 4 demonstrates the SEM micrographs of PA66 (a)-(c) and n-HA/PA66 (d)-(h) specimens after 28 days immersing in SBF. Furthermore, the EDS analysis of n-HA/PA66 was used to clarify the chemical compound of precipitated particles presented on the surface of n-HA/PA66 after immersing in SBF for 28 days. As shown in Figure 4(a)-(c), the surface morphology of PA66 after 28 days soaking in SBF does not show the formation of apatite layer. Therefore, based on SBF results, PA66 has no great potential to show the reaction with bone tissue in biological environment and does have the capability of apatite-bone like form. Hence, it was known as a bio-inert polymer. 
To determine the effect of $\mathrm{n}$-HA on apatite formation ability of PA66 cage, the n-HA 20wt.\% /PA66 was immersed in SBF for 28 days. As can be seen in Figure 4(d)-(h), the precipitates with particles were observed on the surface of n-HA/PA66. The EDS analysis (Figure 4(i)) showed the presence of calcium and phosphor on the surface of this specimen. The average apatite size with a cauliflower-like structure was approximately $2 \mu \mathrm{m}$. In comparison, the obtained bioactivity results of PA66 and n-HA/PA66 cage obviously showed that the apatite formation ability of n-HA/PA66 cage was much higher than that of PA66 cage. It is directly related to the presence of $\mathrm{n}-\mathrm{HA}$ in this specimen.
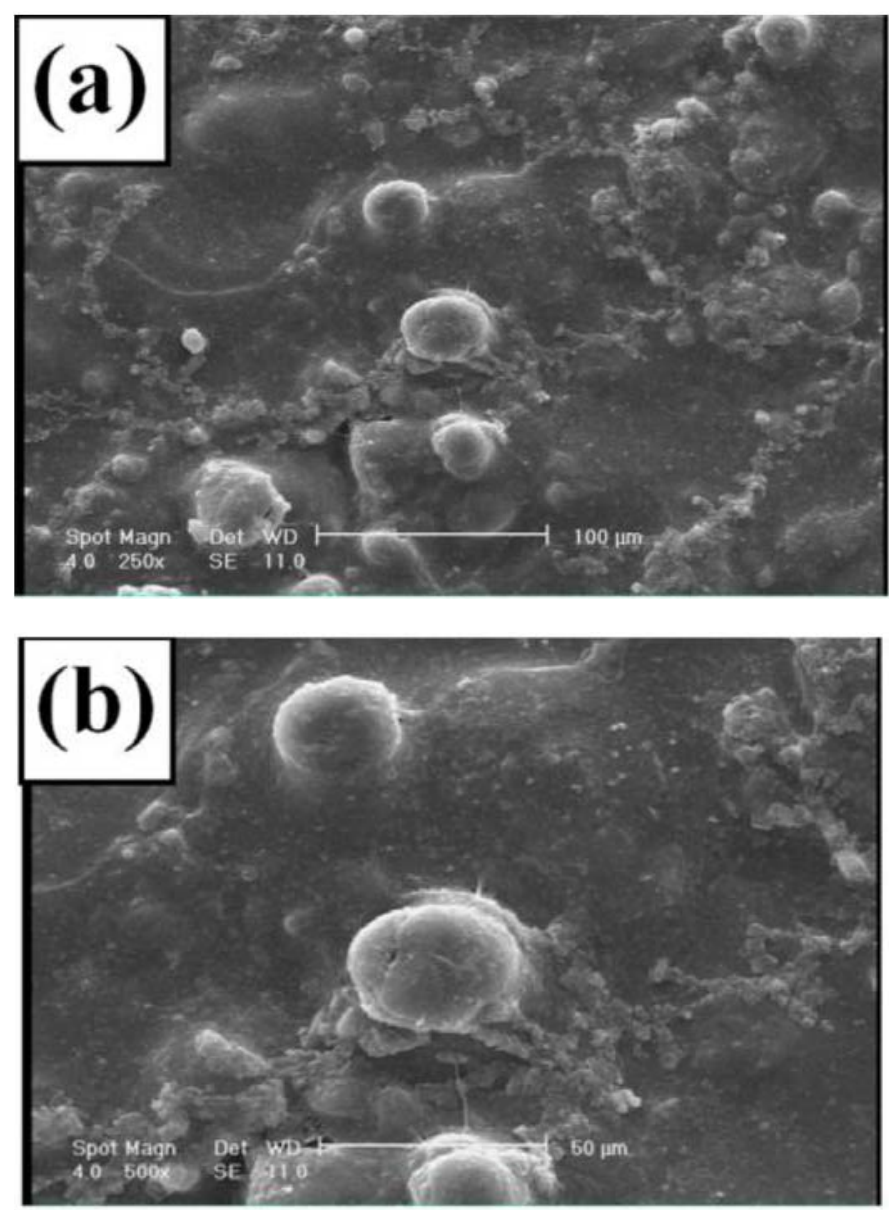

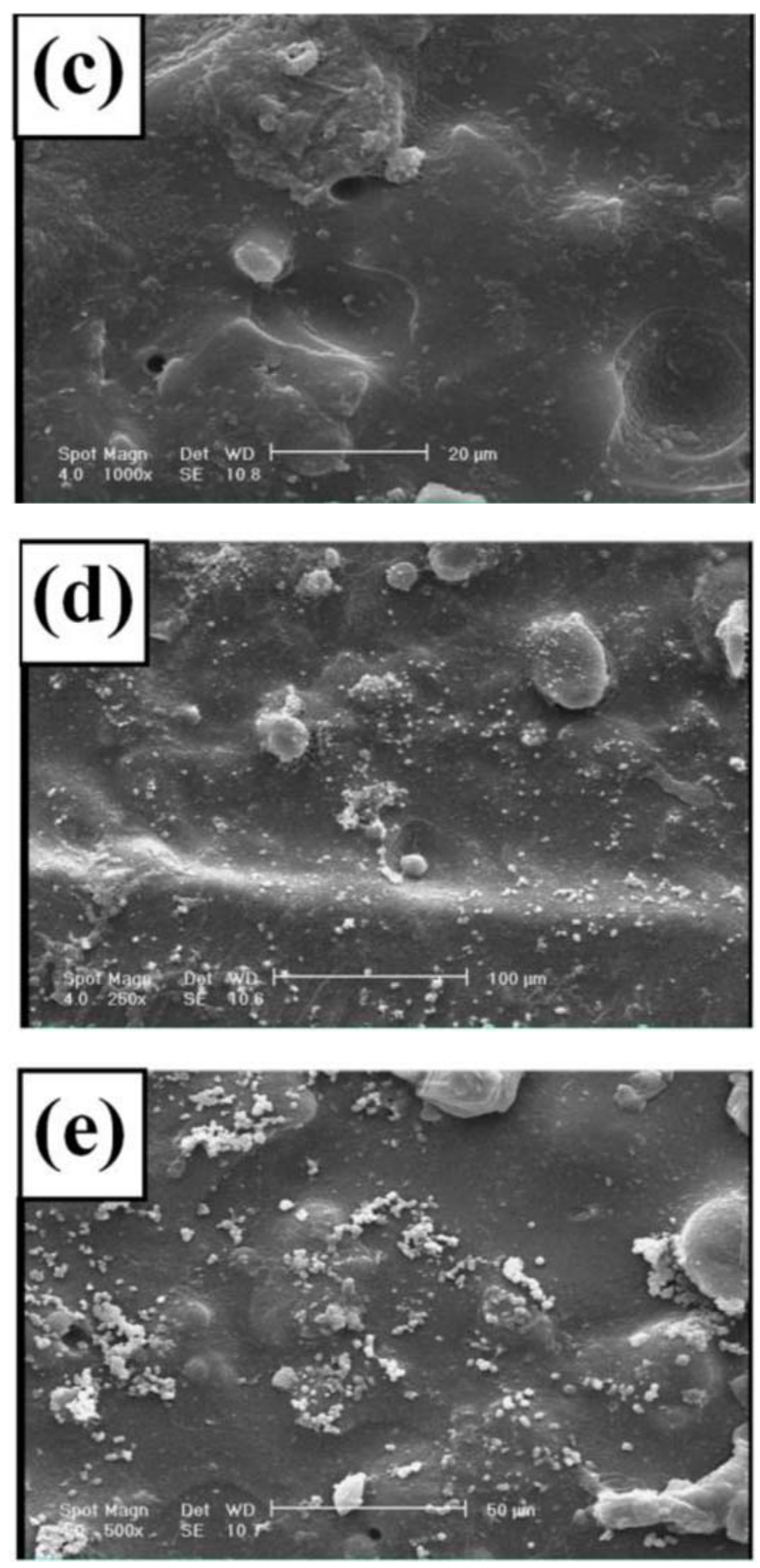

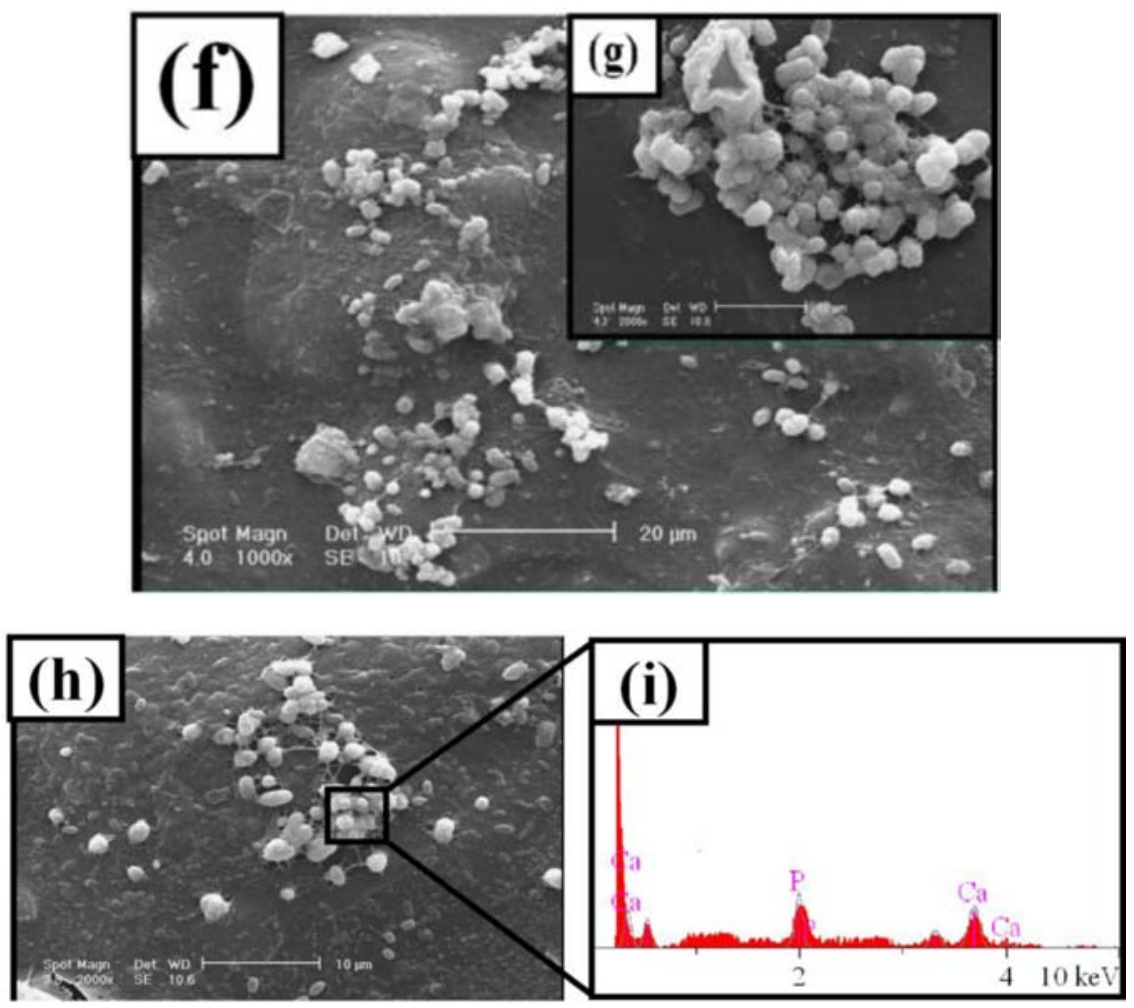

Figure 4. SEM micrograph of (a)-(c) PA66 cage, (d)-(h) n-HA20\%/PA66 and (i) EDS analysis of n-HA20\%/PA66 after 28 days soaking in SBF.

\section{Discussion}

Bone can be considered as nano-composite materials. $35 \%$ of bone is organic ground substances and collagen fibers and 65\% of bone is inorganic (hydroxyapatite). Hydroxyapatite is oriented in the direction of the collagen fibers and collagen is known to nucleate apatite crystals [26]. Despite, the natural bone have the capability of growing and being selfrepairing, if the damage gaps to be bigger than several $\mathrm{mm}$, a bone graft can stimulate healing $[26,27]$.

The cage devises made in the past (polymer, metals and ceramics) could not bond to bone due to their mechanical mismatch (stress shielding phenomenon) or their inert nature [1, 2]. In this study, we 
fabricated the n-HA/PA66 cage with special design to improved its mechanical properties and apatite formation ability by addition of $20 \% \mathrm{n}$ HA in PA66 matrix. The results indicated that n-HA had good interaction with the PA matrix, which is as a results of electrostatic forces and hydrogen bonds existing between the ions and groups in the composite material. These included interactions between the $\mathrm{Ca}^{2+}$ and $\mathrm{PO}^{3-}$ charged groups of $\mathrm{HA}$ and the $-\mathrm{C}-\mathrm{O}$ and $-\mathrm{NH}-$ groups in PA66. Additionally, coordination bonds were formed between the -COO group of PA66 and $\mathrm{Ca}^{2+}$ group of n-HA [6, 10]. Therefore, the improved mechanical properties and apatite formation ability was observed in this composites.

Biomaterials elastic modulus is one of the most important mechanical properties for hard tissue applications. If biomaterials show much higher or lower elastic modulus compared to the native bone tissue, the stress shielding phenomena may occur [21]. As a result, using materials with elastic modulus close to that of human bone is desirable. In the present study, the obtained composite (n-HA/PA66) exhibited a compressive strength of $46.98-90.54 \mathrm{MPa}$ and a modulus of $1.53-8.19 \mathrm{GPa}$, with different designing. It is obvious that the addition of n-HA and changing of designing have a significant effects on the mechanical properties of the n-HA/PA66 composite. Furthermore, the compressive strength and modulus of n-HA/PA66 (Figure 1(b)) was more close to mechanical properties of spongy bone in comparison to peek and other prepared composite in currently study.

Biocompatibility and bioactivity of cage devises are really important. The imperative demand of cage since it works in contact with leaving cells in vitro and with tissue, it must be tolerated in the body and it must not produce an adverse immune response [28]. Previous studies shown that hydroxyapatite/polyamide composite have biological safety, good biocompatibility, and osteoinduction and osseointegration in in vitro and in vivo studies, and have been shown to be a prospective application in 
the clinical setting $[1,2,10]$. Xiong et al. [6] shown the capability of the n-HA/PA66 scaffold composite for bone defect repair. In their study, a retrospective review was carried out for 21 patients who suffer from bone tumor. The radiologic analysis showed that porous n-HA/PA66 composite had been completely incorporated with the host bone about 1.5 years later.

Furthermore n-HA is known as an excellent bioactive material and according to the literature, when it is immersed in the simulated body fluid (SBF), apatite-like calcium phosphates are formed on its surface [29]. Also, its rapid rate of surface reactions, which leads to fast tissue bonding, is another advantage of hydroxyapatite [30]. Therefore, when the n-HA/PA66 cage is used as an implant in the human body, it induces the strong bond to bone and enhances the bone tissue in growth; also stimulates the osteoblast proliferation and differentiation in vitro. Fabrication of n-HA/PA66 cage with improved compressive strength, elastic modulus and apatite formation ability can open a bright horizon to treat the problem of degenerative disc disease.

\section{Conclusion}

This study is the first report of successful design of n-HA/PA66 nanocomposite as an intervertebral fusion cage with improved mechanical and apatite formation ability. Based on the obtained results, addition of $20 \%$ nano $\mathrm{HA}$ to polyamide matrix results in improved compressive strength and elastic modules and close to spongy bone, respectively, compared to PA66 and peek cage. Moreover, the improvement in apatite formation ability and bioactivity of n-HA/PA66 was compared to PA66, and was proved.

\section{Acknowledgements}

The author would like to acknowledge Dr. Emadi and Sadeghzade for their help in preparing this paper. We also thank members of the Materials Science Laboratory of the Isfahan University of Technology for their helpful contributions to this work. 


\section{References}

[1] X. Yang, Y. Song, L. Liu, H. Liu, J. Zeng and F. Pei, Anterior reconstruction with nano-hydroxyapatite/polyamide.e-66 cage after thoracic and lumbar corpectomy, Orthopeedics 35 (2012), 66-73.

[2] Z. Zhao, D. Jiang, Y. Ou, K. Tang, X. Luo and Z. Quan, A hollow cylindrical nanohydroxyapatite/polyamide composite strut for cervical reconstruction after cervical corpectomy, J. Clinical Neurosci. 19 (2012), 536-540.

[3] S. I. Roohani-Esfahani, Y. Chen, J. Shi and H. Zreiqat, Fabrication and characterization of a new, strong and bioactive ceramic scaffold for bone regeneration, Mater. Lett. 107 (2013), 378-381.

[4] Y. Ramaswamy, C. Wu, H. Zhou and H. Zreiqat, Biological response of human bone cells to zinc-modified Ca-Si-based ceramics, Acta Biomaterialia 4 (2008), 1487-1497.

[5] S. I. Roohani-Esfahani, C. R. Dunstan, B. Davies, S. Pearce, R. Williams and H. Zreiqat, Repairing a critical-sized bone defect with highly porous modified and unmodified baghdadite scaffolds, Acta Biomaterialia 8 (2012), 4162-4172.

[6] Y. Xiong, C. Ren, B. Zhang, H. Yang, Y. Lang, L. Min, W. Zhang, F. Pei, Y. Yan, H. Li, A. Mo, C. Tu and H. Duan, Analyzing the behavior of a porous nanohydroxyapatite/polyamide 66 (n-HA/PA66) composite for healing of bone defects, Int. J. Nanomedicine 9 (2014), 485-494.

[7] J. G. Seiler and J. Johnson, Iliac crest autogenous bone grafting: Donor site complications, J. South Orthop. Assoc. 9 (2000), 91-97.

[8] D. W. Hutmacher, J. T. Schantz, L. CX, T. KC and L. TC, State of the art and future directions of scaffold-based bone engineering from a biomaterials perspective, J. Bone Joint Surg. Am. 1 (2007), 245-60.

[9] C. T. Laurencin and L. S. Nair, Nanotechnology and Regenerative Engineering: The Scaffold, Second Edition, CRC Press, New York, 2014.

[10] X. Zhanga, Y. Zhanga, X. Zhangb, Y. Wanga, J. Wanga, M. Lua and H. Li, Mechanical properties and cytocompatibility of carbon fibre reinforced nanohydroxyapatite/polyamide 66 ternary biocomposite, J. Mech. Behave. Biomed. Mater. 42 (2015), 267-273.

[11] W. Jie and L. Yubao, Tissue engineering scaffold material of nano-apatite crystals and polyamide composite, Europe. Polymer J. 40 (2004), 509-515.

[12] Q. Xu, H. Lu, J. Zhang, G. Lu, Z. Deng and A. Mo, Tissue engineering scaffold material of porous nanohydroxyapatite/polyamide 66, Int. J. Nanomedicine 5 (2010), 331-335.

[13] H. Ht, M. Me and H. Rt, Complications of multilevel cervical corpectomies and reconstruction with titanium cages and anterior plating, J. Spinal Disord. 16 (2003), $1-9$. 
[14] J. S. Thalgott, C. Xiongsheng and J. M. Giuffre, Single stage anterior cervical reconstruction with titanium mesh cages, local bone graft, and anterior plating, Spine. J. 3 (2003), 294-300.

[15] M. F. Maitz, Applications of synthetic polymers in clinical medicine, Biosurface and Biotribology 1 (2015), 161-176.

[16] B. M. Willie, A. Petersen, K. Schmidt-Bleek, A. Cipitria, M. Mehta and P. Strube, Designing biomimetic scaffolds for bone regeneration: Why aim for a copy of mature tissue properties if nature uses a different approach? Soft Matter 6 (2010), 4976-4987.

[17] D. Tadic, F. Beckmann, K. Schwarz and M. Epple, A novel method to produce hydroxylapatite objects with interconnecting porosity that avoids sintering, Biomaterial 25 (2004), 3335-3340.

[18] I. Sopyan, M. Mel, S. Ramesh and K. A. Khalid, Porous hydroxyapatite for artificial bone applications, Sci. Techno. Adv. Mater. 8 (2007), 116-123.

[19] S. Sadeghzade, R. Emadi and H. Ghomi, Mechanical alloying synthesis of forsteritediopside nanocomposite powder for using in tissue engineering, Ceram. Silika. 59 (2015), 1-5.

[20] M. Bohner and J. Lemaitre, Can bioactivity be tested in vitro with SBF solution?, Biomaterials 30 (2009), 2175-2179.

[21] S. Sadeghzade, R. Emadi and S. Labbaf, Formation mechanism of nanohardystonite powder prepared by mechanochemical synthesis, Adv. Powder Technol. 27 (2016), 2238-2244.

[22] S. Sadeghzade, R. Emadi, F. Tavangarian and M. Naderi, Fabrication and evaluation of silica-based ceramic scaffolds for hard tissue engineering applications, Mater. Sci. Eng. C 71 (2017), 431-438.

[23] L. C. Gerhardt and A. R. Boccaccini, Bioactive glass and glass-ceramic scaffolds for bone tissue engineering, Mater. 3 (2010), 3867-3910.

[24] A. J. W. Johnson and B. A. Herschler, A review of the mechanical behavior of CaP and $\mathrm{CaP} /$ polymer composites for applications in bone replacement and repair, Acta Biomater. 7 (2011), 16-30.

[25] S. Sadeghzade, F. Shamoradi, R. Emadi and F. Tavangarian, Fabrication and characterization of baghdadite nanostructured scaffolds by space holder method, J. mech. Behave. Biomed. Mater. 68 (2017), 1-7.

[26] F. Schwarz, A. Sculean, K. Bieling, D. Ferrari, D. Rothamel and J. Becker, Two-year clinical results following treatment of periimplantitis lesions using a nanocrystalline hydroxyapatite or a natural bone mineral in combination with a collagen membrane, J. Clin. Periodontol. 35 (2008), 80-87.

[27] P. V. Giannoudis, H. Dinopoulos and E. Tsiridis, Bone substitutes: An update, Injury 36 (2005), 20-27. 
[28] C. Gualandi, Porous Polymeric Bioresorbable Scaffolds for Tissue Engineering, Springer Thesis, Italy, 2011.

[29] H. Zhang and B. W. Darvell, Constitution and morphology of hydroxyapatite whiskers prepared using amine additives, J. Europ. Ceram. Soc. 30 (2010), 2041-2048.

[30] I. Cacciotti, A. Bianco, M. Lombardi and L. Montanaro, Mg-substituted hydroxyapatite nanopowders: Synthesis, thermal stability and sintering behaviour, J. Europ. Ceram. Soc. 29 (2009), 2969-2978. 